Original Article

\title{
RELATIONSHIP OF BODY FAT PERCENTAGE AND APO B/APO A-1 RATIO AS CARDIOVASCULAR RISK MARKER IN RURAL ADULTS OF YOGYAKARTA INDONESIA
}

\author{
FENTY, ARIS WIDAYATI, PHEBE HENDRA* \\ Faculty of Pharmacy Universitas Sanata Dharma Yogyakarta, Indonesia \\ Email: phebe_hendra@usd.ac.id
}

Received: 25 Oct 2016 Revised and Accepted: 07 Dec 2016

\section{ABSTRACT}

Objective: Prevalence of obesity and cardiovascular disease has increased in both urban and rural areas Indonesia. High body fat percentage (BF\%) is associated with a high cardio metabolic risk. The apolipoproteins (Apo) B/Apo A-1 ratio is a better risk predictor for cardiovascular disease. This study aimed to explore the relationship of BF\% and Apo B/Apo A-1 ratio among rural adults in Yogyakarta Indonesia.

Methods: This cross-sectional study included 40 men and 62 women (40-60 y old). Those who had cardiometabolic diseases, edema or currently taking cardio metabolic medicines were excluded. Information about sociodemographic details was obtained by using a self-administerd questionnaire. The questionnaire also assessed smoking status, reproductive history and medical history. Anthropometric measurement, apo B, Apo A-1, fasting blood glucose and blood pressure were measured.

Results: The prevalence of high $\mathrm{BF} \%$ was $12.7 \%$ and $6.9 \%$ in men and women, respectively. There was negative correlation between $\mathrm{BF} \%$ and apo $\mathrm{A}-1$ and positive correlation between $\mathrm{BF} \%$ and apo $\mathrm{B}$ as well as $\mathrm{BF} \%$ and apo $\mathrm{B} / \mathrm{apo} \mathrm{A}-1$ ratio. A significant weak correlation was observed between BF\%-apo B/apo A-1 ratio in women (r: 0.280; p: 0.027).

Conclusion: BF\% is associated with apo B/apo A-1 ratio among women adults in rural area of Yogyakarta Indonesia findings support the importance of using $\mathrm{BF} \%$ to predict cardiovascular disease in rural area.

Keywords: Body Fat Percentage, Apo B/apo A-1 ratio, Relationship

(C) 2017 The Authors. Published by Innovare Academic Sciences Pvt Ltd. This is an open access article under the CC BY license (http://creativecommons.org/licenses/by/4. 0/) DOI: http://dx.doi.org/10.22159/ijpps.2017v9i2.15864

\section{INTRODUCTION}

The prevalence of obesity and cardiovascular disease (CVD) has increased in developing countries, including Indonesia [1-3]. Based on the household health survey in Indonesia (2004), the study demonstrated that the prevalence of overweight was $7.2 \%$ and $10.4 \%$ for men and women, respectively. The prevalence of overweight was higher in urban areas $(10.8 \%)$ than in rural areas (7.5\%) [1]. A national survey showed that the highest incidence of central obesity was $36.9 \%$ among adults 45 to $54 \mathrm{y}$ old, and the percentage of abnormal low-density lipoprotein (LDL) and highdensity lipoprotein (HDL) profile is more prevalent in rural Indonesia. The CVD prevalence was greater in urban compared with rural population (23.4\% and $19.5 \%$, respectively) [2]. Another study indicated that the prevalence of prehypertension and hypertension were relative high among young Indonesian adults in primary health care of rural area [4]. Our previous study found that prevalence of metabolic syndrome in rural areas of Yogyakarta was 25\%, female more prevalent than male subjects [5]. According to World Health Organization (WHO), more than 1.9 billion adults ( $\geq 18$ y) were overweight in 2014, and of this, over 600 million were obese [6]. The increased of obesity is closely associated with elevated risk of CVD and obesity is an independent risk factor for all-cause mortality as well as for CVD $[7,8]$.

Frequently, obesity is diagnosed using body mass index (BMI), however this measurement has been criticized because could not identify fat distribution and low specificity regarding body composition [9, 10]. Deurenberg-Yap et al. [11,12] who studied Singaporean adults confirmed the high BF\% increases the risk factor for CVD in normal and low-BMI and the relationship between BF\% and BMI is different among three ethnic groups in Singapore; whereas Kim et al. [13] who studied Korean reported the same. Body fat percentage as anthro pometric measurement has not been extensively used in epidemiological studies in Indonesia. Our unpublished study showed that there was significant correlation between $\mathrm{BF} \%$ with lipid ratio as a CVD risk factor in the urban adolescents and in rural adult's area.

Apolipoproteins are proteins associated with lipids in lipoprotein particles. The ratio of apolipoprotein B (apo B) and apo A-1 represents the balance between apo B-rich potentially atherogenic cholesterol particles and apo A-1-rich antiatherogenic cholesterol particles. The apo B/apo A-1 ratio are the best predictor of CVD related to lipids as compared with other lipids ratio [14].

Other studies have reported apo B/apo A-1 ratio might be of greatest value in diagnosis and treatment in people who have common lipid abnormalities, but have normal or low concentrations of LDL-cholesterol [15]. People with the unfavorable apo B/apo A-1 had more atherogenic lipid profile, therefore apo B/apo A-1 ratio can be considered as a sensitive marker of atherogenic risk [16].

In this study, we determined the relationship of $\mathrm{BF} \%$ and ratio apo B/apo A-1 among rural adult people in Indonesia.

\section{MATERIALS AND METHODS}

\section{Design and sample}

This cross-sectional evaluation was carried out in Cangkringan SubDistric, a rural area in Yogyakarta Indonesia. This study was conducted from June 2016 to August 2016 involved a total number of 102 adults people who lived in Cangkringan. Adults aged 40 to 60 y were eligible to participate in the study after signing a written consent form according to Helsinki Declaration.

Those who had cardiometabolic diseases, edema or currently taking cardio metabolic medicines were excluded. Each subject gave a written informed consent for participating in the study, which was approved with approval number KE/FK/048/EC/2016. by Medical and Health Research Ethics Committee (MHREC) Faculty of Medicine Gadjah Mada University Indonesia. 


\section{Measurements}

Measurements were taken using standardized equipment Anthropometric measurements, biochemical assessments and selfreported questionnaire were used for data collection. Clinical data including blood pressure (BP) was also obtained. Biochemica assessments included estimation of fasting blood glucose, apo A-1 and apo B. The questionnaire was constructed to assess sociodemographic details, smoking habits, reproductive history and medical history.

$\mathrm{BF} \%$ was determined by the sum of the thickness of three skinfolds (triceps, suprailiac, and abdominal), measured using a Skinfold Caliper (Pzi dou fi ${ }^{\circledR}$ ) and calculated by Siri's equation [17-19]. We used a modified Jackson-Pollock 3-site equation because the 3-site equation analysis method is simpler and faster than other methods. Previous study showed there was a strong correlation between the equation and dual-energy X-ray absorptiometry (DEXA) as a gold standard $\left(\mathrm{R}^{2}=0.98, \mathrm{p}: 0.0001\right)$ [20]. Based on American College of Sports Medicine (ACSM's), BF\% associated with optimal health of $20-32 \%$ for women and $10-22 \%$ for men [21-22].

Blood sample were collected from the subjects by registered nurses in the morning after a fasting period of $10-12 \mathrm{~h}$. The apo A1, apo B and fasting blood glucose were measured on Architect Ci8200intergrated-system (Abbott Laboratories, USA) in certified laboratory of Yogyakarta.
BP was measured using a digital automatic apparatus (Omron, HEM7203, Japan), in a sitting position. Two measurements were taken with interval of 3 min between consecutive measurements.

\section{Statistical analysis}

Statistical analysis was done using SPSS version 20.0. Continuous variables are expressed as mean \pm standard deviation (SD) if data were distributed normally) or median (minimum-maximum) if data were not distributed normally. Categorical variable were expressed as percentages. The statistical significance of differences in subjects cardiovascular risk factors based on $\mathrm{BF} \%$ was analyzed using the ANOVA test. Correlations between the indices were assessed using the Spearman`s rank correlation. A p-value of less than 0.05 was considered as statistically significant.

\section{RESULTS}

Using purposive sampling technique a total of 102 adults were recruited, men were $39 \%$ and women were $61 \%$. The characteristics of study participants were summarized in table $1 . \mathrm{BF} \%$ of men and women were $17.9 \pm 0.9$ and $26.5 \pm 0.8$ respectively. Among men and women, systole arterial pressure, diastolic arterial pressure, fasting blood glucose levels were comparable. Serum apo A1 as expression of plasma HDL levels was higher in women than men. Apo B as expression of LDL was lower in women than men subjects. Apo B/apo A-1 ratio were higher in men compared to women subjects.

Table 1: Characteristics of study participants

\begin{tabular}{lll}
\hline Variables & Men (N=40) & Women (N=62) \\
\hline Age (y) & $51.6 \pm 0.8$ & $48.0 \pm 0.7$ \\
Body Fat Percentage (\%) & $17.9 \pm 0.9$ & $26.2 \pm 0.8$ \\
Systole arterial pressure (mmHg) & $133.5(98.5-196.5)$ & $138.8 \pm 2.9$ \\
Diastolic arterial pressure (mmHg) & $80.5 \pm 1.7$ & $82.7 \pm 1.5$ \\
Fasting blood glucose (mg/dl) & $81(62-276)$ & $82.5(68-220)$ \\
Apo A-1 (mg/dl) & $129.1 \pm 2.5$ & $134.4 \pm 2.2$ \\
Apo B (mg/dl) & $98.3(63.7-180.5)$ & $92.0 \pm 3.0$ \\
Apo B/Apo A-1 ratio & $0.75(0.5-1.0)$ & $0.7(0.3-1.3)$ \\
\hline
\end{tabular}

Table 2 shows, in women, there are 13 obese $(12.7 \%) ; 37$ normal (36.3\%); 12 underweight (11.8\%), respectively. In men, there are 7 obese (6.9\%); 31 normal (30.4\%); 2 underweight (1.9\%), respectively. Based on BF\%, the overall prevalence of obese (ACSM) was $19.6 \%$ in rural area of Yogyakarta Indonesia. Women $(12.7 \%)$ showed higher prevalence when compared with men $(6.9 \%)$.

Table 2: Prevalence of obesity among adult in rural area based on BF\%

\begin{tabular}{llll}
\hline Subjects & Prevalence (\%) & & Total \\
\cline { 2 - 5 } & Women & Men & 13.7 \\
\hline Underweight & 11.8 & 30.4 & 66.7 \\
Normal & 36.3 & 6.9 & 19.6 \\
Obese & 12.7 & & \\
\hline
\end{tabular}

Table 3: Spearman correlation coefficients between the apo A1, apo B, apo B/apo A-1 ratio and BF\%

\begin{tabular}{lllll}
\hline & BF\% & & & Women \\
\hline & Men & & Spearman, $\mathbf{r}$ & P-level \\
\hline apo A-1 & Spearman, $\mathbf{r}$ & $\boldsymbol{P}$-level & -0.141 & 0.247 \\
apo B & -0.264 & 0.100 & 0.240 & 0.060 \\
apo B/apo A-1 & 0.080 & 0.224 & 0.280 & 0.027 \\
\hline
\end{tabular}

Among men and women, there was significant negative correlation between $\mathrm{BF} \%$ and apo $\mathrm{A}-1$ and positive correlation between $\mathrm{BF} \%$ and apo $\mathrm{B}$ as well as BF\% and apo B/apo A-1ratio (table 3). A significant weak correlation was also observed between BF\% and apo B/apo A-1 in women $(\mathrm{p}<0.05)$.

\section{DISCUSSION}

In our study, we examined the relationship between $\mathrm{BF} \%$ and apo $\mathrm{B} /$ apo $\mathrm{A} 1$ ratio as a better marker for predicting CVD than conventional another marker.
Prevalence of obese based on $\mathrm{BF} \%$ according is $19.6 \%$ in rural area of Yogyakarta Indonesia, whereas women more prevalent than men. Similar findings have been reported in other studies that obesity prevalence was higher in women than men according to $\mathrm{BF} \%[9,13,23-25]$. 
Our study demonstrated that BF\% had negative correlation with apo A-1 and positive correlation with apo B and apo B/apo A-1 ratio. Only apo B/apo A-1 ratio showed significant weak correlation with $\mathrm{BF} \%$ in women subjects ( $\mathrm{r}$ : 0.280; p: 0.027). Previous studies showed $\mathrm{BF} \%$ was only weakly associated with predicted CVD risk compare to other body composition indices and body mass index and waist-to-hip ratio were better predictors of CVD risk than $\mathrm{BF} \%$ $[26,27]$. Although the correlation between $\mathrm{BF} \%$ and apoB/apo A-1 ratio was weak, however this finding strengthen that $\mathrm{BF} \%$ is associated with cardio metabolic risks.

Our study has a few limitations. Firstly, the small number of subjects with cross-sectional design may be unable to provide strong and significant correlation. The directionally of the correlation can be suggested. Secondly, we used skinfold thicknesses measurement to measure $\mathrm{BF} \%$. DEXA as a gold standard to measure $\mathrm{BF} \%$, but it is not used commonly in clinical setting because it is expensive and inconvenient [13]. However, another study showed strong correlation between the modified Jackson-Pollock 3-site equation and DEXA [20]. Thirdly, the results of this study cannot be generalized to other population because the subjects were adults only between 40-60 y in rural area with different socio-cultural characteristics from other population.

\section{CONCLUSION}

Our results demonstrate that $\mathrm{BF} \%$ is weakly associated with apo B/apo A-1 ratio among women adults in rural area of Yogyakarta Indonesia. However these findings support the importance of using $\mathrm{BF} \%$ in to predict cardiovascular disease in rural area.

\section{ACKNOWLEDGEMENT}

This research project was supported by a grant from Ministry of Research, Technology and Higher Education of the Republic of Indonesia with contract number 010/HB-LIT/III.2016. Study participants at Cangkringan Sub-Distric, Yogyakarta Indonesia are greatly acknowledged.

\section{CONFLICT OF INTERESTS}

Declared none

\section{REFERENCES}

1. Sandjaja, Sudikno. Prevalence of overweight and obesity in adults Indonesia. Gizi Indonesia 2005;31:1-7.

2. Ministry of Health Republic of Indonesia. Riset Kesehatan Dasar Indonesia Jakarta 2013;5:258-60.

3. Popkin BM. Does global obesity represent a global public health challenge? Am J Clin Nutr 2011;93:232-3.

4. Widjaja FF, Santoso LA, Barus NRV, Pradana GA, Estetika C. Prehypertension and hypertension among young indonesian adults at a primary health care in a rural area. Med J Indian 2013;22:39-45.

5. Fenty, Widayati A, Virginia DM, Hendra P. Metabolic syndrome among adults in rural areas. Indonesian J Clin Pathol Med Laboratory 2016;22:254-7.

6. World Health Organization. Obesity and Overweight, Fact Sheet $\mathrm{N}{ }^{\circ} 311$; 2015. Available from: http://www.who.int/ mediacentre/factsheets/fs311/en/ [Last accessed on $10 \mathrm{Feb} 2016$ ].

7. Lavie CJ, Milani RV, Ventura HO. Obesity and cardiovascular disease: risk factor, paradox, and impact of weight loss. J Am Coll Cardiol 2009;53:1925-32.

8. Jiang J, Ahn J, Huang WY, Hayes RB. Association of obesity with cardiovascular disease in the PLCO trial. Prev Med 2013;57:60-4.

9. Valentino G, Bustamante MJ, Orellana L, Kramer V, Duran S, Adasme M, et al. Body fat and its relationship with clustering of cardiovascular risk factor. Nutr Hosp 2015;31:2253-60.
10. WHO expert consultation. Appropiate body mass index for asian population and its implication for policy and intervention strategies. Lancet 2004;363:157-63.

11. Deurenberg-Yap M, Chew S, Deurenberg P. Elevated body fat percentage and cardiovascular risks at low body mass index levels among Singaporean Chinese, Malays, and Indians. Obes Rev 2002;3:209-15.

12. Deurenberg-Yap M, Schmidt G, van Staveren WA, Deurenberg P. The paradox of low body mass index and high body fat percentage among Chinese, Malays and Indians in Singapore. Int J Obesity Related Metab Disorders 2000;24:1011-7.

13. Kim JY, Han SH, Yang BM. Implication of high-body-fat percentage on cardiometabolic risk in middle aged, healthy, normal weight adults. Obesity 2013;21:1571-7.

14. Dawar R, Gurtoo A, Singh R. Apo B/Apo A1 ratio is statistically the best predictor of myocardial infarction compared to other lipid ratios. Int J Pharma Biosci 2010;1:1-8.

15. Walldius, Jungner I, Holme I, Aastveit AH, Kolar W, Steiner E. High apolipoprotein B, low apolipoprotein A1, and improvement in the prediction of fatal myocardial infarction (AMORIS study): a prospective study. Lancet 2001;358:2026-33.

16. Kaneva AM, Potolitsyna NN, Bojko ER, Odland JO. The apolipoprotein B/apolipoprotein A-1 ratio as a potential marker of plasma atherogenicity. Dis Markers 2015. http://dx.doi.org/10.1155/2015/591454.

17. Sailaja AK. An overall review on obesity and its related disorders. Innovare J Life Sci 2015;3:1-3.

18. National Health and Nutrition Examination Survey (NHANES), Antropometry Procedures Manual, CDC, U. S.; 2007. p. 1-1, 1-2.

19. Hoeger WWK, Hoeger SA. Principles and Labs for Fitness and Wellnes. 12th Ed. Wadsworth Cengage Learning, USA; 2014. p. 126, 132, 142.

20. Shakibaee A, Faghihzadeh S, Alishiri GH, Ebrahimpour Z, Faradjzadeh S, Sobhani V, et al. How accurate are the anthropometry equations in Iranian military men in predicting body composition? Asian J Sports Med 2015;6:e23206.

21. Esmat T. Measuring and Evaluating Body Composition; 2016. Available from: http://www.acsm.org/public-information/ articles/2016/10/07/measuring-and-evaluating-bodycomposition. [Last accessed on 10 Feb 2016]

22. Rahl RV. Physical Activity and Health Guidelines Recommendations for Various Ages, Fitness level and Condition From 57 Authoritative Sources; 2010. p. 252.

23. Habib SS. Body mass index and body fat percentage in assessment of obesity prevalence in Saudi Adults. Biomed Environ Sci 2013:26:94-9.

24. Amin F, Fatima SS, Islam N, Gilan AH. Prevalence of obesity and overweight, its clinal markers and associated factors in a high risk South-Asian population. BMC Obese 2015;2:16.

25. Ho-Pham LT, Lai TQ, Nguyen MTT, Nguyen TV. Relationship between body mass index and percent body fat in vietnamese: implications for the diagnosis of obesity. PLoS One 2015; 10: e0127198.

26. Su TT, Amiri M, Hairi FH, Thangiah N, Dahlui M, Majid HA. Body composition indices and predicted cardiovascular disease risk profile among urban dwellers in Malaysia. BioMed Res Int 2015;201-7. http://dx.doi.org/10.1155/2015/174821

27. Myint PK, Kwok CS, Luben RN, Wareham NJ, Khaw KT. Body fat percentage, bodymass index and waist-to-hip ratio, as predictors of mortality and cardiovascular disease. Heart 2014;100:1613-9.

\section{How to cite this article}

- Fenty, Aris Widayati, Phebe Hendra. Relationship of body fat percentage and Apo B/Apo A-1 ratio as cardiovascular risk marker in rural adults of Yogyakarta Indonesia. Int J Pharm Pharm Sci 2017;9(2):114-116. 